\title{
hydra
}

\section{VOLTARAVIRASER,ABUSCADAANCESTRALIDADEESQUECIDA:ACAPOEIRAEA ÉTICADAORGANIZAČ̃ADOSGRUPOS}

\author{
Renata Giovana de A. Martielo'
}

\begin{abstract}
Resumo: Temos registro da existência da prática da capoeira no Brasil desde o século XIX. Uma expressão cultural e filosófica de matriz africana que resistiu à colonização europeia imbricada nos processos históricos e sociais que fizeram parte da vida de africanos(as) no Brasil. Pensando a capoeira como território de respeito às diferenças e de alteridade, esse artigo busca compreender como os grupos de capoeira foram influenciados pela lógica individualista e excludente do sistema capitalista na modernidade/colonialidade, e analisar os efeitos dessa influência na ética da organização dos grupos, a partir da análise dos recentes casos de abuso de ordem moral e sexual praticados por mestres de um dos maiores grupos de capoeira da atualidade. Além disso, busca também projetar outras possibilidades epistemológicas, com base no perspectivismo africano e na pluriversalidade de suas filosofias, para podermos pensar o que poderíamos voltar a vir a ser. $O$ artigo conclui que há um afastamento dos praticantes de capoeira das epistemologias que estruturaram essa expressão cultural afro-brasileira e que, somado a isso, a influência dos valores da modernidade/colonialidade vem degenerando as relações humanas dentro dos grandes grupos de capoeira.
\end{abstract}

Palavras-chave: Capoeira; Colonialidade; Ancestralidade.

\section{TO COME BACK TO BEING, THE SEARCH FOR FORGOTTENANCESTRY: CAPOEIRA ANDTHEETHICS OFORGANIZING GROUPS}

\begin{abstract}
Wa have records of the existence of practice of capoeira in Brazil since the 19th century. A cultural and philosophical expression of African matrix that resisted the European colonization intertwined with the historical ande social processes that were part of the life of Africans in Brazil. Thinking capoeira as a territory of respect for diferences and otherness, this article seeks to understand how capoeira groups were influenced by the individualistic and excluding logic of the capitalist system in modernity/coloniality, and to analyze the effects of this influence on the ethics of the organization of groups a starting from the analysis of recente cases of abuse of moral and sexual nature practiced by mestres of onde of the largest groups today. It also seeks to Project Other epistemological possibilities based on African perspectivism and pluriversality of its philosophies, so that we can think about what we could become again. The article concludes that there is a distancing of capoeira practitioners from tha epistemologies that structured this Afro-Brazilian cultural
\end{abstract}

\footnotetext{
'Mestranda em filosofia pela UFRJ http://lattes.cnpa.br/8924814102302750, mestra de
} capoeira formada pelo Grupo Senzala - M. Peixinho. 


\section{hydra}

expression. And that, added to this influence of values of modernity/coloniality has been degenerating human relations within large capoeira groups.

Keyword: Capoeira; Coloniality; Ancestry.

\section{Introdução}

Houve um tempo em que a capoeira foi uma das manifestações culturais brasileiras mais estudadas e debatidas, ela mereceu quilômetros de tinta em jornais, revistas e livros (SOARES, 1993).²

Estamos de volta ao frenesi da mídia, pois veio a público, recentemente, casos de abuso sexual e moral por parte de mestres de capoeira de um dos maiores grupos de capoeira do Brasil e do mundo. Segundo as informações do jornal Gl, do Ceará e TV Verdes Mares, publicado em 07/06/2021,3 desde 2020 o Ministério Público do Estado do Ceará (MPCE) investiga esses casos e cerca de dez vítimas fizeram acusações contra vários mestres. Esses atos, segundo consta na reportagem, foram praticados sistematicamente, ao longo de anos, durante a formação na capoeira de crianças e jovens.

Frente a esses desafios impostos à livre expressão da capoeira, observo, atentamente, o crescimento de ações que desvalorizam aspectos estruturantes dessa prática secular, que emerge no meio urbano brasileiro nos primórdios da colonização europeia (PIRES, 2010;

\footnotetext{
2 SOARES, Carlos Eugênio Líbano. A negregada instituição: os capoeiras no Rio de Janeiro 1850-1890. 1993. 2v. Dissertação (mestrado) - Universidade Estadual de Campinas, Instituto de Filosofia e Ciências Humanas, Campinas, São Paulo, 1993, p.14. Disponível em: http://www.repositorio.unicamp.br/handle/REPOSIP/279422. Acesso em 20/06/2021.

3MPCE recebe novas denúncias de abuso sexual contra mestres de capoeira. gl.globo.com, 2021. Disponível em: <https://gl.globo.com/ce/ceara/noticia/2021/06/07/mpce-recebe-novasdenuncias-de-abuso-sexual-contra-mestres-de-capoeira.ghtml>. Acesso em 10/06/2021.
} 


\section{hydra}

SOARES, 2004). ${ }^{4}$ Pensando a capoeira como território de respeito às diferenças e de alteridade, esse artigo busca compreender como uma lógica individualista e excludente tem influenciado as organizações de capoeira a ponto de provocar tamanhos desvios éticos de seus praticantes.

Compreendo a capoeira como uma expressão filosófica afrobrasileira, estruturada em uma pluralidade de perspectivas epistêmicas em contrapartida à universalização dos saberes proposto pelo modelo civilizatório europeu, e considerando a base da filosofia africana na filosofia do Ubuntu, "justamente como o solo, a raiz, os ramos e folhas, juntas como unicidade dão significado para nosso entendimento da árvore, assim é com ubuntu" (RAMOSE, 1999, p.1). ${ }^{5}$ Percebo a capoeira caminhando em descompasso com sua gênese e origem africana, pois "ser um humano é afirmar sua humanidade por reconhecimento da humanidade de outros e, sobre estas bases, estabelecer relações humanas com os outros" (RAMOSE, 1999, p.3).6

A capoeira, para se fazer presente nos corpos, exige que as existências dialoguem em harmonia, para que o giro da roda aconteça. Assim sendo, não consigo deixar de pautar algumas questões: a capoeira, gestada como expressão da liberdade, estará de tal forma ocidentalizada que seus praticantes já não têm mais nenhuma conexão

\footnotetext{
4 PIRES, Antonio Liberac Cardoso Simões. Culturas circulares. A formação histórica da capoeira contemporânea no Rio de Janeiro. $1^{a}$ edição, Curitiba: Editora Progressiva, 2010, Fundação Jair Moura, Salvador, 2010, p.25.

SOARES, Carlos Eugênio Líbano. A capoeira escrava e outras tradições rebeldes no Rio de Janeiro (1808 - 1850). $2^{a}$ ed, Campinas, SP: Editora Unicamp, 2004, p.74.

5 RAMOSE, Mogobe Bernard. AfricanPhilosophythrough Ubuntu. Harare: Mond Books, 1999, p. 49-66. Tradução para uso didático por Arnaldo Vasconcellos. Disponível em: https://docplayer.com.br/12384521-A-filosofia-do-ubuntu-e-ubuntu-como-umafilosofia-mogobe-b-ramose.html.

66 RAMOSE, Mogobe Bernard. AfricanPhilosophythrough Ubuntu. Harare: Mond Books, 1999, p. 49-66. Tradução para uso didático por Arnaldo Vasconcellos. Disponível em: https://docplayer.com.br/12384521-A-filosofia-do-ubuntu-e-ubuntu-como-umafilosofia-mogobe-b-ramose.html
} 


\section{$\underline{\text { hydra }}$}

com as epistemologias fundantes da sua prática? Serão os capoeiristas contemporâneos meros fantoches de um sistema que privilegia as vontades individuais e que as desumaniza e aliena? Desde quando esse tipo de valores humanos vem pautando a capoeira, ou sempre estiveram nela? Jogamos capoeira para quem e porquê? Estaremos nós vivendo o tempo das perguntas fortes e das respostas fracas? "Os tempos de transição são, por definição, tempos de perguntas fortes e respostas fracas."7 Acredito que essa terrivel experiência humana que estamos vivendo, através das notícias dos abusos de poder nas organizações dos grupos de capoeira, está na ordem das questões sobre modernidade/colonialidade na capoeira.

Extermínio, expropriação, dominação, exploração, morte prematura e condições que são piores que a morte, tais como a tortura e o estupro, são ações predominantes nos conflitos beligerantes... Na modernidade/colonialidade, todas essas ações ocorrem permanentemente, não como uma resposta a conflitos específicos, mas como formas de estar em acordo com a ordem percebida da natureza e do mundo (TORRES, 2020). 8

Compreendendo a capoeira como uma prática plural e buscando esclarecer o lugar de onde essa ordem está sendo percebida vou situar o meu lugar de fala.

\footnotetext{
7 As perguntas fortes dirigem-se não só às nossas opções de vida individual e coletiva, mas sobretudo às fundações que criam o horizonte de possibilidades entre as quais é possível escolher. São, portanto, questões que provocam um tipo particular de perplexidade. As respostas fracas são aquelas que procuram responder sem pôr em causa o horizonte de possibilidades, imaginando nele virtualidades para esgotar 0 campo das perguntas e das respostas possíveis ou legítimas. SANTOS, Boaventura de Sousa. A filosofia à venda, a douta ignorância e a aposta de Pascal. Revista Crítica de Ciências Sociais, 80, Coimbra, 2008, p.11-43. Disponível em: $<$ https://journals.openedition.org/rccs/691> Acesso em 20/06/2021.

8TORRES, Nelson Maldonado in: COSTA, Jaoze Bernardino; TORRES, Nelson Maldonado; GROSFOGUEL, Ramón. Decolonialidade e pensamento afrodiaspórico. $2^{a}$ edição, Belo Horizonte: Autêntica, 2020, p.41.
} 


\section{$\underline{\text { hydra }}$}

\section{Limpando o terreiro}

Seria uma incoerência se esse artigo incorresse no erro epistemológico de generalizar a capoeira assim, como as epistemologias filosóficas africanas. Por isso afirmo que se trata de uma capoeira que caminha no fio de existência entre a escola de capoeira angola, fundada por mestre Pastinha, e a capoeira da escola de mestre Bimba, algo próximo de uma criação que surgiu na década de 60, no Rio de Janeiro, no qual fez uma releitura dessas duas expressões corporais, filosóficas e políticas. Essa releitura da capoeira brasileira, que não é nem angola e nem regional, serviu de base para inúmeras escolas de capoeira gestarem suas propostas. É desse lugar que escrevo, por mais que, sendo aparentemente um problema da ordem da organização das estruturas sociais na modernidade/colonialidade, possivelmente encontraremos exemplos de degeneração dos valores estruturantes da capoeira em todas as modalidades de capoeira existentes.

Com relação a filosofia, antes de pensar argumentos que se fundamentem em uma ou outra etnia ou território africano, sugiro pensarmos nos modelos criativos e includentes de convivência social, que foram gestados em território brasileiro a partir das experiências africanas e indígenas as quais nos estruturaram. De acordo com Soares, ${ }^{9}$ a etnia que identificava os africanos escravizados no século XIX estava mais relacionada ao porto onde foram embarcados do que efetivamente a origem em África. Porém, é importante ressaltar que no ano de 1810 encontramos a primeira referência a um africano preso por capoeira pela Guarda Real de Polícia, do príncipe dom João, o dito cujo aparece identificado como sendo da nação Angola. Para além, 


\section{hydra}

ainda com Soares, 10 temos nos africanos congos um papel de relevo na composição das maltas. " Na capoeira temos uma relação estreita com o aumento de energia vital, as rodas de capoeira muitas vezes são classificadas como muito boas por terem produzido um alto nível de energia, característica das filosofias Bantu, que compreendem a existência como movimento da força vital de cada indivíduo e do coletivo como um todo, visto que é a comunidade que define a pessoa. De acordo com Oliveira:

A cultura bantu (outro exemplo africano), em síntese, baseiase no aumento da força. A ontologia dos povos austrais africanos não se ocupa com substâncias e essências, com objetos e suas propriedades ou com a matéria e seus desdobramentos. Ela se ocupa do aumento ou da diminuição da força vital (OLIVEIRA, 2021).12

Dito isso, reconheço na capoeira a forte influência dos povos Bantu vindos de Angola.

\section{Prazer e felicidade como meta}

Vamos dar uma repaginada nessa busca pelo prazer e pela felicidade, vamos ao espanto filosófico! Para o pé do berimbau, ${ }^{13}$ convido o filósofo Epicuro que vai auxiliar-nos a fazer escolhas com mais sabedoria através da sua ética. Fazendo um jogo de apresentação,

\footnotetext{
10 SOARES, Carlos Eugênio Líbano. A capoeira escrava e outras tradições rebeldes no Rio de Janeiro (1808 - 1850). $2^{a}$ ed, Campinas, SP: Editora Unicamp, 2004.

11 Maltas eram grupos de capoeiristas do Rio de Janeiro que tiveram seu auge na segunda metade do século XIX. Compostas principalmente de negros e mulatos, as maltas lutavam resistiam contra o sistema, a elite carioca da época. PIRES, Antonio Liberac Cardoso Simões. Culturas circulares. A formação histórica da capoeira contemporânea no Rio de Janeiro. $1^{a}$ edição, Curitiba: Editora Progressiva, 2010, Fundação Jair Moura, Salvador, 2010, p.24-25.

12OLIVEIRA, Eduardo David de. Filosofia da ancestralidade: Corpo e Mito na Filosofia da Educação Brasileira. $1^{a}$ edição, Rio de Janeiro: Ape'ku, 2021, p.240.

13 Local onde os capoeiristas agachados aguardam o início do jogo.
} 


\section{$\underline{\text { hydra }}$}

conhecido na capoeira como jogo solo, Epicuro de Samos, filósofo grego do período Helenístico, viveu entre 341 a.e.c. e 270 a.e.c., sua filosofia da busca do prazer e da felicidade nos chega através da Carta a Meneceu. Sem fazer distinções de origem social, o epicurismo leva em consideração o fortalecimento coletivo, a união das pessoas sob valores supremos como a amizade, a colaboração e a liberdade. Valores esses que muito dialogam com a capoeira.

Esse filósofo nos diz que prazer não deve ser confundido com a busca pura e simples da realização de todos os desejos, para Epicuro, essa busca deve ser cuidadosa e racional, nenhum prazer deve ser descolado das virtudes pessoais, não pode causar perturbações e nem dores no futuro. A busca por um prazer imediato deve antes passar pela reflexão sobre a prudência.

Praticar ações de prazer moderado no presente, mas que perdurem no tempo bastaria para fazer desses capoeiras um mestre ou uma mestra a ser lembrado no futuro por um trabalho significativo, essa é uma busca que devemos considerar na capoeira.

Na sua gênese, a roda da capoeira precisa ser compreendida como um espaço de ajuda mútua e colaboração que provoca diferentes sensações nos participantes, os da roda de dentro sentem de forma epidérmica os toques do berimbau, reagem as mensagens dos corpos em movimento, percebem o agitar das suas células em momentos cruciais do jogo, já os da roda de fora, são traspassados por sensações que, às vezes, não sabem definir, mas que os remete a cheiros, amores, lugares e são igualmente afetados por essa energia vital que circula no ambiente. Saber apreciar os prazeres da roda da capoeira é uma tarefa que aprendemos com o tempo.

Assim, tendo como valor civilizatório a oralidade e, nesta, uma base forte de transmissão de conhecimentos na capoeira, ser mestre ou 


\section{$\underline{\text { hydra }}$}

mestra nessa arte exige a dedicação de uma vida. Espera-se que os mestres e as mestras sejam os guardiões dos saberes acumulados no tempo vivido na capoeira.

\section{Ancestralidade e alienação dos sujeitos}

Para falar do tempo como mestre, precisamos findar esse jogo solo e chamar para a roda um camarada que já estava na bateria, 14 Eduardo Oliveira, que nos brinda com belas reflexões acerca do sentido e significado de ancestralidade, corpo encantamento, mito e rito, além do conceito de ginga para a capoeira. Com o berimbau gunga ${ }^{15} \mathrm{em}$ riste, fazemos a chamada ${ }^{16}$ para agradecer o solo de Epicuro e chamar ao pé do berimbau o Eduardo Oliveira. Mas como não se joga capoeira sozinho, o gunga pensa, e convoca Karl Marx para esse jogo epistêmico. Karl Marx foi um filósofo, sociólogo, historiador, economista, jornalista e revolucionário socialista atuante em meados do século XIX. Poderia ficar aqui narrando a performance desses capoeiras, e podem ter certeza que será um jogo memorável, mas vou direto ao ponto.

Como sistema político social, o capitalismo nos dá mostras de falência, visto que degenera o ser humano em sua capacidade de pensar o outro, a vida coletiva, a equidade de acesso aos bens produzidos pelo capital e está estruturado em uma política de

\footnotetext{
14 Nome dado a organização dos instrumentos musicais que compõem a roda de capoeira.

15 Berimbau que emite a tonalidade mais grave, costuma ser o instrumento que fica na mão do capoeira responsável por comandar a roda, definir quando um jogo acaba e começa outro, quando os capoeiras precisam vir ao pé do berimbau.

16 Uso de um toque específico para alertar os jogadores que estão dentro da roda da capoeira sobre a necessidade de virem ao pé do berimbau. Pode ser para findar o jogo e começar outro, pode ser para uma orientação sobre o jogo, pode ser para que ajeitem suas vestimentas, enfim, são vários os motivos que levam o berimbau gunga a fazer uma chamada.
} 


\section{$\underline{\text { hydra }}$}

dominação e exploração do ecossistema, ao nível de colocar em risco a experiência humana na Terra.

Na segunda metade do século XIX, O desenvolvimento cultural produziu alterações no modo de produção e na forma de trabalho humano, características da sociedade capitalista liberal que foram aplicadas às artes em geral. A transformação do homem ou das suas ideias em coisa, bem ou produto, faz o que os teóricos da Escola de Frankfurt17 chamam de coisificação e alienam os sujeitos das suas vontades.

A cultura vista como algo passível de ser produzida em série, para um grande número de pessoas, abre mão da sua característica crítica para ser mais um produto que pode ser trocado por dinheiro. Da cultura de massa para indústria cultural, vemos a capoeira dar um grande salto em direção a sedução do sistema capitalista e suas promessas de riqueza. As organizações de capoeira, que antes eram pequenos grupos de pessoas que seguiam um mestre ou mestra por respeito e admiração, crescem em número de adeptos e passam a ser grupos gigantes que se espalham por todo o mundo. Agora é a lógica do consumo no mercado que rege a produção cultural.

Nosso mundo está doente, os seres humanos estão cada vez mais alienados $^{18}$ de sua humanidade. Nossos valores estão pautados pelos bens que adquirimos e que poderemos adquirir: um carro novo, um

\footnotetext{
17 Os pensadores da Escola de Frankfurt analisaram e denunciaram algumas estruturas de dominação política, econômica, cultural e psicológica da sociedade moderna. Demonstraram de forma explícita a capacidade destrutiva do capitalismo, principal responsável pela estagnação da consciência política, crítica e revolucionária. MEDEIROS, Alexandro M. Escola de Frankfurt. Sabedoria Política, 2014. Disponível em: < https://www.sabedoriapolitica.com.br/filosofia-politica/filosofiacontempor\%C3\%A2nea/escola-de-frankfurt/> Acesso em: 08/07/2021.

18 Comer, beber e procriar são, evidentemente, também funções genuinamente humanas. Mas, consideradas abstratamente, à parte do ambiente de outras atividades humanas, e convertidas em fins definitivos e exclusivos, são funções animais. MARX, Karl. Manuscritos econômico-filosóficos, primeiro manuscrito, XXIII. Disponível em: <Manuscritos Econômico-Filosóficos (marxists.org) > Acesso em 20/06/2021.
} 


\section{hydra}

celular novo, um tênis novo. É isso que pauta a humanidade de uma pessoa? Nos perdemos na busca desenfreada por sensações?

Alienar-se de si mesmo é obra do capitalismo, mas o reencontro de sua subjetividade, de seus sentidos está no âmbito do reconhecimento de quem nós somos, de onde viemos e para onde desejamos ir. Voltamos, assim, à filosofia do Ubuntu para pensar a capoeira como uma grande árvore, de raízes profundas e que gera diversos frutos ao longo de sua existência. Assim deveria estar a capoeira, num espaço onde o presente, passado e futuro jogam juntos em uma só roda, e vem Oliveira e nos diz que "em momentos agudos de crise urge ressaltar outros modelos de organização da vida (OLIVEIRA, 2021). ${ }^{19}$

Pensar a capoeira, como uma expressão filosófica que tem seus olhos mirando o passado, como o Sankofa20, deveria nos conectar com todos e todas que nos antecederam e trazer para o presente a certeza de que meus atos precisam respeitar meus antepassados, precisam produzir mais energia vital, honrar quem me antecedeu e se perpetuar na memória futura.

Nesse momento acontece uma compra súbita do jogo, pois a filósofa Katiúscia Ribeiro entende que seu jogo de capoeira com Eduardo Oliveira vai produzir um diálogo muito mais proveitoso para o pensamento da ancestralidade do que o do velho Marx. A "mestra"

\footnotetext{
19OLIVEIRA, Eduardo David de. Cosmovisão africana no Brasil: elementos para uma filosofia afrodescendente. $1^{a}$ edição, Rio de Janeiro: Ape'ku, 2021 p.33.

200 conceito de Sankofa (Sanko = voltar; $f a=$ buscar, trazer) origina-se de um provérbio tradicional entre os povos de língua Akan da África Ocidental, em Gana, Togo e Costa do Marfim. Em Akan "se wo were fi na wosan kofa a yenki" que pode ser traduzido por "não é tabu voltar atrás e buscar o que esqueceu". Projeto sankofa discute as questões e relações étnico-raciais. Portal.fiocruz.br, 2018. Disponível em: $<$ https://portal.fiocruz.br/noticia/projeto-sankofa-discute-questoes-e-relacoes-etnicoraciais\#: : :text=0\%20conceito\%20de\%20Sankofa\%20/Sanko,e\%20buscar\%200\%20que \%20esqueceu\%E2\%80\%9D>. Acesso em 28/06/2021.
} 


\section{hydra}

vem com tudo para o jogo argumentando como os ensinamentos ancestrais podem reconectar a sociedade atual com sua essência.

Nesse momento o encantamento é inevitável, pois

[...] O encantamento é a função da ancestralidade... Encantamento tem a ver com olhar. O olhar encantado constrói um mundo encantado. Se a modernidade produziu o desencantamento do mundo, a ancestralidade produz um mundo encantado (OLIVEIRA, 2021).21

Eduardo compreende a oportunidade que tem de jogar com a "mestra" e amiga e inicia seu jogo dando golpes que mostram como que, no caso da cosmovisão africana, educa-se para a ética do encantamento, e provoca: "educar é conhecer a partir das referências culturais que estão no horizonte de minha história (ancestralidade)" (OLIVEIRA, 2021).22

A "mestra" aceita a provocação, mas negaceia 23 para um lado, floreia, ${ }^{24}$ e experimenta uma resposta. Assim que abre na ginga, todos têm a certeza que com as mestras não se vacila na roda, Ribeiro nos fala de tempos antigos, pelos quais valores como "sabedoria e prudência implicam o conhecimento (rekhet) e a consciência dos princípios da conduta moral e do comportamento sociável" (RIBEIRO, 2020). ${ }^{25}$ Com movimentos que muitos participantes jamais viram na roda, a "mestra" nos apresenta conceitos milenares, elaborados por

\footnotetext{
21 OLIVEIRA, Eduardo David de. Filosofia da ancestralidade: Corpo e Mito na Filosofia da Educação Brasileira. $1^{a}$ edição, Rio de Janeiro: Ape'ku, 2021, p. 260.

22 OLIVEIRA, Eduardo David de. Filosofia da ancestralidade: Corpo e Mito na Filosofia da Educação Brasileira. $1^{a}$ edição, Rio de Janeiro: Ape'ku, 2021, p. 261.

23 Fazer uma negativa na capoeira é negar por alguns instantes os golpes que vieram, é ganhar tempo para pensar o jogo, é dissimular o que se deseja fazer.

24 Florear no jogo da capoeira é fazer movimentos acrobáticos conhecidos como floreios.

25 RIBEIRO, Katiúscia et al. Rekhet: Um exercício que transcende o ato de filosofar.

Revista Ítaca, n.36, Rio de Janeiro, 2020, p. 51-53
} 


\section{hydra}

nossos ancestrais, os quais precisamos relembrar, a fim de encontrar caminhos para escapar dessas armadilhas da colonialidade.

É entender a dimensão do 'outro' como parte da natureza. É preciso entender a unicidade. Para tanto, a pessoa sábia (rekhética) precisa ser humilde para escutar, sobretudo os mais velhos, pedir conselhos, buscar em si mesma a sabedoria, ou seja, experienciar a própria vida, uma vida que não está desconectada da comunidade em que vive, uma vida que não existe o não-ser, uma em que o 'outro' faz parte, pois todos estão envolvidos nesse mesmo movimento da natureza (RIBEIRO, 2020).26

Será que a situação problema foi não terem buscado em si mesmos a sabedoria? Será que sabiam que essa sabedoria estava lá? Esses mestres abusadores perderam a noção da dimensão do outro como parte do todo, da natureza?

\section{A capoeira}

Aqui quero deixar explícito que a capoeira precisa ser desenvolvida como um conceito filosófico, pois é quase uma entidade e que, na maioria das vezes, não tem nada a ver com os atos praticados por seus integrantes, atos que atentam contra a humanidade das pessoas e que dizem respeito tão somente a falta de conhecimento deles sobre si mesmos. É preciso compreender a capoeira enquanto um ancestral nosso, que existe desde sempre, e que se revela todos os dias junto com o nascer do sol. Sua sabedoria vem do outro lado do oceano, marcada em nossos corpos, na batida dos nossos corações, em uma memória epidérmica e, por certo, ainda não conseguimos desvendar todos os seus ensinamentos. Aponto para o epistemicídio produzido

\footnotetext{
${ }^{26}$ RIBEIRO, Katiúscia et al. Rekhet: Um exercício que transcende o ato de filosofar.
} Revista Ítaca, n.36, Rio de Janeiro, 2020, p.53. 


\section{hydra}

pela imposição das epistemologias ocidentais como responsável direto por essa dificuldade que temos de nos conectar com nossos saberes ancestrais.

Estará a nossa capoeira doente de falta de valores de ancestralidade, mas não pensem que me refiro somente ao fato de os capoeiras estarem sob ataque midiático nesse momento, ataques estes que não caíram do céu, foram fabricados por homens doentes de tanta sociedade, e por que não dizer por mulheres doentes de ocidente também? O que fizeram de nós?

\section{Masculinidades tóxicas}

Refletindo a formação de mestra na capoeira, tenho pouco mais de 35 anos de prática, relembrei das inúmeras vezes que fiquei abaixada ao pé do berimbau aguardando minha vez de jogar e aguardava que os homens parassem de comprar o jogo na minha frente, talvez se alguém intercedesse por mim e autorizasse minha entrada na roda, eu provavelmente jogaria uns poucos miúdos de segundos, pois para permanecer na roda, no centro do espetáculo, era preciso que eu batesse ou apanhasse. Como, muitas vezes, eu não conseguia acertar meu (minha) oponente logo de primeira tentativa, e nem permitia que ele (ela) me acertasse, o jogo rapidamente seria comprado.27 Como eu ficava? Pensa! Grata e feliz por terem me concedido esses miúdos de tempo dentro da roda! Depois ficaria por horas contemplando os viris, másculos, fortes, sarados homens jogando, ou tentaria iniciar todo esse processo novamente. Agora os jovens devem estar pensando, mas por que ela não se impunha, não bancava

\footnotetext{
${ }_{27}$ Comprar o jogo significa entrar uma terceira pessoa na roda e retirar uma das pessoas que estava jogando.
} 


\section{$\underline{\text { hydra }}$}

a entrada na roda na marra? Hoje tenho várias respostas para essa colocação, mas na ocasião eu saía realmente grata por ter quase jogado, era natural que uma jovem menina de 15 anos agisse assim, era o esperado. Estava internalizado na minha formação ocidentalizada que meu lugar era aquele, o de respeitar os homens, os mais velhos, os que chegaram primeiro na capoeira (que pese que até os meninos pequenos compravam na minha frente), os que "jogavam mais e melhor que eu". Não se deixem enganar pensando que a questão era sobre treinar mais, para em um dado momento ser digna de jogar o tempo que quisesse. $O$ buraco era bem mais fundo!

Se formos refletir o conceito de gênero construído no ocidente a partir das teorias feministas veremos que "estudiosas feministas são a mais importante circunscrição com foco em gênero e a fonte de muito conhecimento sobre as mulheres e hierarquias de gênero" (OYĚWùMí, 2004). ${ }^{28}$

Nas sociedades colonizadas americanas, a unidade de análise do conceito de gênero é sempre o lar da família nuclear, o que então, teoricamente, reduz mulher à esposa. Dito isso, percebo através do relato de experiência citado, como mulheres e homens capoeiristas foram imbricados pela estrutura política social vigente no ocidente o qual se adota essa conceituação de gênero, fixando seus papéis e naturalizando a subalternidade da mulher. A família nuclear judaico cristã se fixou nos corpos e mentes das capoeiras, nas suas atitudes, nas suas pernadas.

Esse ponto me parece ser um tema de urgência na direção de construir relações humanas saudáveis na capoeira e na sociedade brasileira. Temos que construir novas referências para compreensão

\footnotetext{
28 OYĚWÙMí, Oyèrónké. Conceituando o Gênero: Os fundamentos eurocêntricos dos conceitos feministas e o desafio das epistemologias africanas. CODESRIA Gender Series. Dakar, CODESRIA, 2004. P.2.
} 


\section{hydra}

humana das relações entre os gêneros. Oyěwùmí fala a partir da sociedade lorubá do sudoeste da Nigéria e apresenta um tipo diferente de organização familiar, pelo qual o princípio organizador fundamental no seio da família é antiguidade, baseada na idade relativa, e não de gênero. As categorias de parentesco codificam antiguidade, e não gênero (OYĚWÙMí, 2021). ${ }^{29}$ Reconhecimento do saber dos mais velhos, suas existências possuem representatividade para a comunidade, assim como a relação com a ancestralidade. Tornar-se mais velho na capoeira é o maior bem que se pode alcançar. "Os ancestrais, portanto, é a referência cultural maior para orientar as ações do grupo" (OLIVEIRA, 2021).30

A capoeira conhece bem essa antiguidade, ser mais antigo é ser mais prestigiado, ter mais poder, ser mais respeitado, por serem mestres e mestras, por sua vivência e experiência, pelo acúmulo de capoeira em suas mentes e corpos, mas foi exatamente nesse espaço de conexão com a ancestralidade, de respeito e confiança na maestria que se concretizaram os abusos, nos quais as vulnerabilidades foram expostas.

Penso em quantas coisas os mestres podem conseguir com seus alunos jovens, adolescentes e crianças. Para além das regras sociais internalizadas, das regras historicamente construídas, há uma enorme admiração pelo mestre, uma imensa necessidade de estar inserido no contexto, de fazer parte daquela elite que pode jogar mais tempo, que viaja com os mestres, que é convidado para dar aulas em eventos, que poderá ser protagonista.

\footnotetext{
29 OYĚWÙMÍ, Oyèrónké. A invenção das mulheres: construindo um sentido Africano para os discursos ocidentais de gênero. $1^{a}$ edição, Rio de Janeiro: Bazar do Tempo, 2021.

30 OLIVEIRA, Eduardo David de. Filosofia da ancestralidade: Corpo e Mito na Filosofia da Educação Brasileira. $1^{a}$ edição, Rio de Janeiro: Ape'ku, 2021, p.267.
} 


\section{hydra}

Preciso traçar uma reflexão com vocês a partir daqui. Existe, desde a década de 80, do século XX, pelo menos, uma busca para que a capoeira possa ser o meio de sobrevivência financeira para seus praticantes e suas famílias. Assim sendo, colocamos a capoeira nas escolas, nos clubes, academias e tiramos das praças e ruas (que pese que, até que enfim, estamos fazendo o caminho de volta), e encontramos caminhos para levar a capoeira para outros países. Bem, se aqui no Brasil a capoeira já estava sendo uma boa opção de mercadoria a ser comercializada, no exterior ganha status de mercadoria tipo exportação. Para essa relação comercial se efetivar, as organizações de capoeira começaram a filtrar o que seria produto comercial e o que seria ocultado da prática da capoeira.

Trompe-l'oeil, traduzido literalmente como engana olho, é na verdade uma simulação do real. Essa expressão foi utilizada por Muniz Sodré para explicar como se deu o "desenvolvimento ideológico brasileiro, isto é, a evolução das formas da consciência dominante no Brasil" (SODRÉ, 2019).31 A ideia que quero provocar aqui, a partir da leitura do Sodré, se refere à presença da capoeira nas primeiras horas em espaços europeus. Faz-se necessário pensar o continente Europeu e seu papel na desarticulação política e social do continente africano, passando pelo período colonial, e se consolidando na diáspora. O que nossos praticantes de capoeira estão ensinando no estrangeiro? Filosofias de matriz africana, estamos falando das interfaces da capoeira com o candomblé, falamos das cosmologias dos reinos africanos, das sociedades matrilineares, da horizontalidade do poder, dos saberes ancestrais? Ou estamos exportando o que melhor vende: algumas pernadas sem sentido, sem conexão com a história da

${ }^{31}$ SODRÉ, Muniz. O terreiro e a cidade: a forma social negro-brasileira. $3^{a}$ edição, Rio de Janeiro: Mavad X, 2019, p.35. 


\title{
hydra
}

capoeira, com muitos e muitos floreios (saltos acrobáticos), com direito

a vender os instrumentos e uniformes superfaturados, o samba fetichizado, a dança dos orixás que também vende bem, não é mesmo?

Se formos pensar sobre quais são os países envolvidos no apagamento das etnias escravizadas no Brasil, a dimensão disso é muito grande.

\begin{abstract}
A unilateralidade da história oficial foi incapaz de perceber a grandeza de outras civilizações. Com o olhar voltado para o próprio umbigo, ignorou e aniquilou histórias milenares. O que para o Outro foi a história dos descobrimentos para Nós foi a história do apagamento (NASCIMENTO e NASCIMENTO, 2008). .32
\end{abstract}

A provocação que faço aqui é exatamente essa que você está pensando, os descendentes de nossos algozes do passado portugueses, franceses, alemães, dinamarqueses, holandeses, espanhóis - (é difícil achar um país europeu que não estava naquela Conferência em Berlim, ávido por um pedacinho da riqueza que havia para explorar) - são os que hoje compram a capoeira de nós em moeda estrangeira. Será que estamos fazendo um trabalho consciente, ou mandingando com a Europa em uma espécie de contrapartida enviesada na volta que o mundo deu, ou estamos apenas apresentando nosso dever de casa bem feito?

O fato é que os tentáculos do sistema capitalista que envolveram as culturas e os capoeiras há décadas, estão na base da organização dos grandes grupos. Os valores ancestrais foram esquecidos e em seu lugar estão ideologias que deturpam a ética e a estética da capoeira.

\footnotetext{
32 NASCIMENTO, Gizêlda Melo do. e NASCIMENTO, Elisa Larkin. In: NASCIMENTO, Elisa Larkin (org.). A matriz africana no mundo. São Paulo: Selo Negro, 2008, p. 135.
} 


\section{hydra}

A capoeira sofre por ver seus praticantes dedicados ao culto ao corpo, a individualização, a busca por superar o outro, por estar inserido, ser parte da "elite", se destacar. Esses mestres encontraram justificativas nesse sistema para subjugarem seus iniciantes, negociaram suas humanidades em troca da possibilidade de viajar, ter um lugar para trabalhar no exterior, ser reconhecido na capoeira em meio a tantos outros bons capoeiristas. Negociaram a própria ética e levaram a capoeira com eles. Como muito bem nos ensinou a poesia de Césaire (1978): "A Europa é indefensável".33 E quem se afina com seus valores, deturpando os valores originais da capoeira, também!

\section{O que poderíamos voltar a vir a ser?}

Convido a todos agora para pensar a partir de valores civilizatórios afro-brasileiros. ${ }^{34}$ Oralidade, musicalidade, circularidade, energia vital, afetividade, ancestralidade, cooperatividade são apenas alguns dos valores que nossos irmãos e irmãs africanos deixaram fluindo aqui em terras brasileiras. Fundamentar nossa prática de capoeira em torno dos valores que a fundaram, valores daqueles que a trouxeram em forma bruta, é um bom começo para pensar no que queremos com a nossa capoeira.

Capoeira pressupõe trabalho em grupo, harmonia, parceria, respeito a todos e todas que por aqui passaram, a todo sangue derramado, a toda comunidade desfeita, criança assassinada, mulher

\footnotetext{
${ }_{33}$ CÉSAIRE, Aimé. Discurso sobre o colonialismo. $1^{a}$ edição, Lisboa: Livraria Sá da Costa Editora, 1978, p. 13.

34 TRINDADE, Azoilda Loretto da (org.). Documentário: Africanidades brasileiras e educação. Conbi.tvescola.org.br, 2013. Disponível em: https://cdnbi.tvescola.org.br/contents/document/publicationsSeries/182537Doc_afric anidades.pdf > Acesso em 18/06/2021.
} 


\section{hydra}

estrupada, a toda mazela que foi impetrada, a todo assassinato cultural que foi feito, a toda sorte de violência pela qual nossos irmãos e irmãs escravizados foram submetidos.

Portanto, afirmo que nossa capoeiragem precisa voltar a vir a ser africanizada, ler a capoeira a partir de outras perspectivas, cosmopercepções e cosmologias ancestrais precisam pautar nossa prática. Para que isso ocorra, temos que decolonizar nosso pensamento, lutar bravamente contra o ocidente que nos habita.

Precisamos compreender que a colonização europeia se deu, e ainda se dá, nas frestas, nas brechas do jogo, naquele golpe fora do tempo. Desde o primeiro homem europeu que aqui aportou, colonizaram nossos sistemas jurídicos, políticos, ideológicos, religiosos e culturais. Quem não fizer o exercício de olhar para trás e reontologizar seus passos na história com régua e compasso africano, estará sujeito a continuar perdido em uma lógica excludente, competitiva, individualizante. Esses capoeiristas foram engolidos pela lógica do mercado, se venderam, deturparam seus valores morais em nome de um suposto progresso econômico. Estamos progredindo em que área da vida humana? Corpos negros são mortos diariamente nas ruas e vielas, não nos apropriamos dos bens produzidos pelo capital e a produção desses bens está destruindo nosso planeta. Naturalizamos a violência, esses mestres levaram a busca por prazer ao limite, destruíram vidas de famílias inteiras com suas violências.

Precisamos restaurar as vozes e as experiências subalternas, ouvir o som que vem das memórias coletivas, romper com o silêncio que está sufocando os capoeiristas, enfrentar o silêncio de nossas bocas, aceitar o som que vem de dentro e nos diz que tudo isso está errado. Valorizar a cultura popular, a sabedoria dos antigos, avançar juntos, de mãos 


\section{hydra}

dadas em direção a essência da nossa capoeira. Porque "tudo o que nós tem é nós! E é tudo para ontem".35

"Tenho sangrado demais, tenho chorado para cachorro. Ano passado eu morri, mas esse ano eu não morro!"36

\section{REFERÊNCIAS}

AMARELO - É tudo pra ontem. Direção: Fred Ouro Preto. Produção de Evandro Fióti do Laboratório Fantasma em parceria com a Nefflix. Local: São Paulo. Distribuidora Netflix, 2020.

BELCHIOR, Antônio Carlos. Sujeito de Sorte in: BELCHIOR, Antônio Carlos. Álbum: Alucinação, 1976.

CÉSAIRE, Aimé. Discurso sobre o colonialismo. $1^{a}$ edição, Lisboa: Livraria Sá da Costa Editora, 1978.

COSTA, Jaoze Bernardino; TORRES, Nelson Maldonado; GROSFOGUEL, Ramón. Decolonialidade e pensamento afrodiaspórico. $2^{a}$ edição, Belo Horizonte: Autêntica, 2020.

LOPES, Claudemira Vieira Gusmão. O que Fomos (África Pré-Colonial)? O que Fizeram de nós (Colonialismo)? O que Poderemos Voltar a Vir a Ser (Educação para a Descolonização dos Saberes)? Periódicos UFPE-Revista Interritórios, v.06, n¹2, Pernambuco, 280-298, 2020.2 Disponível em: https://periodicos.ufpe.br/revistas/interritorios/article/view/249001. Acesso em: 20/06/2021.

MARX, Karl. Manuscritos econômico-filosóficos, primeiro manuscrito, XXIII. Marxists.org, $2007 . \quad$ Disponivel em: https://www.marxists.org/portugues/marx/1844/manuscritos/cap01.htm.

Acesso em 20/06/2021.

MEDEIROS, Alexandro Melo. Escola de Frankfurt. Sabedoria Política, 2014. Disponível em: $\quad$ https://www.sabedoriapolitica.com.br/filosofiapolitica/filosofia-contempor\%C3\%A2nea/escola-de-frankfurt/. Acesso em: 08/07/2021.

MPCE recebe novas denúncias de abuso sexual contra mestres de capoeira. G1, Ceará, 07 jun. 2021. Notícias. Disponível em: https://gl.globo.com/ce/ceara/noticia/2021/06/07/mpce-recebe-novasdenuncias-de-abuso-sexual-contra-mestres-de-capoeira.ghtml. Acesso em 10/06/2021.

35 AMARELO. Direção: Fred Ouro Preto. Produção de Evandro Fióti do Laboratório Fantasma em parceria com a Nefflix. Local: São Paulo, Brasil: Distribuidora Netflix do filme Emicida: Amarelo - É Tudo Pra Ontem, 2020. Netflix.

36 BELCHIOR, Antônio Carlos. Sujeito de Sorte in: BELCHIOR, Antônio Carlos. Álbum: Alucinação, 1976. 


\section{$\underline{\text { hydra }}$}

NASCIMENTO, Elisa Larkin (org.). A matriz africana no mundo. São Paulo: Selo Negro, 2008.

OLIVEIRA, Eduardo David de. Cosmovisão africana no Brasil: elementos para uma filosofia afrodescendente. $1^{a}$ edição, Rio de Janeiro: Ape'ku, 2021.

OLIVEIRA, Eduardo David de. Filosofia da ancestralidade: Corpo e Mito na Filosofia da Educação Brasileira. $1^{a}$ edição, Rio de Janeiro: Ape'ku, 2021.

OYĚWÙMÍ, Oyèrónké. Conceituando o Gênero: Os fundamentos eurocêntricos dos conceitos feministas e o desafio das epistemologias africanas. CODESRIA

Gender Series. Dakar, CODESRIA, 2004. Disponível em: https://ayalaboratorio.files.wordpress.com/2019/06/conceito-genero.pdf.

Acesso em: 28/06/2021.

OYĚWÙMÍ, Oyèrónké. A invenção das mulheres: construindo um sentido Africano para os discursos ocidentais de gênero. $1^{a}$ edição, Rio de Janeiro: Bazar do Tempo, 2021.

PIRES, Antonio Liberac Cardoso Simões. Culturas circulares. A formação histórica da capoeira contemporânea no Rio de Janeiro. $1^{a}$ edição, Curitiba: Editora Progressiva, 2010, Fundação Jair Moura, Salvador, 2010.

Projeto Sankofa discute as questões e relações étnico-raciais. Portal Fiocruz, 2018. Disponível em: https://portal.fiocruz.br/noticia/projeto-sankofa-discutequestoes-e-relacoes-etnico-

raciais\#: : :text=0\%20conceito\%20de\%20Sankofa\%20/Sanko,e\%20buscar\%200 \%20que\%20esqueceu\%E2\%80\%9D. Acesso em 28/06/2021.

RAMOSE, Mogobe Bernard. AfricanPhilosophythrough Ubuntu. Harare: Mond Books, 1999, p. 49-66. Tradução para uso didático por Arnaldo Vasconcellos. Disponível em: https://docplayer.com.br/12384521-A-filosofia-do-ubuntu-eubuntu-como-uma-filosofia-mogobe-b-ramose.html. Acesso: 10/06/2021.

RIBEIRO, Katiúscia et al. Rekhet: Um exercício que transcende o ato de filosofar. Revista Ítaca, n.36, Rio de Janeiro, 2020, p. 51-53; Disponível em: https://revistas.ufrj.br/index.php/ltaca/article/view/31985/19766. Acesso em: 28/06/2021.

RIBEIRO, Katiúscia. O laboratório de filosofia africana geru maã na UFRJ e os desafios para produção de conhecimento sobre filosofia africana e as relações raciais. Revista Encantar, v.1, n. 1, Bahia 2019, p. 09-27; Disponível em: https://www.revistas.uneb.br/index.php/encantar/article/view/8080. Acesso em: 28/06/2021.

SANTOS, Boaventura de Sousa. A filosofia à venda, a douta ignorância e a aposta de Pascal. Revista Crítica de Ciências Sociais, 80, Coimbra, 2008, p.1143. Disponível em: https://journals.openedition.org/rccs/691. Acesso em 20/06/2021.

SOARES, Carlos Eugênio Líbano. A capoeira escrava e outras tradições rebeldes no Rio de Janeiro (1808-1850). $2^{\mathrm{a} e d}$, Campinas, SP: Editora Unicamp, 2004.

SOARES, Carlos Eugênio Líbano. A negregada instituição: os capoeiras no Rio de Janeiro 1850-1890. 1993. 2v. Dissertação (mestrado) - Universidade Estadual de Campinas, Instituto de Filosofia e Ciências Humanas, Campinas, São Paulo, 1993.

Disponível

em: 


\section{hydra}

http://www.repositorio.unicamp.br/handle/REPOSIP/279422. Acesso em 20/06/2021.

SODRÉ, Muniz. O terreiro e a cidade: a forma social negro-brasileira. $3^{a}$ edição, Rio de Janeiro: Mauad X, 2019.

TRINDADE, Azoilda Loretto da (org.). Documentário: Africanidades brasileiras e educação. CDNBI TV escola, 2013. Disponível em: https://cdnbi.tvescola.org.br/contents/document/publicationsSeries/182537D oc africanidades.pdf. Acesso em 18/06/2021.

Artigo recebido em 02/07/2021 e aprovado em 07/09/2021. 